\title{
Posmononocoor
}

2014, vol. 71, 93-99

http://dx.doi.org/10.12657/denbio.071.009

\author{
Grzegorz Iszkuło, Kinga Nowak-Dyjeta, Maciej Sękiewicz
}

\section{Influence of initial light intensity and deer browsing on Taxus baccata saplings: a six years field study}

Received: 11 March 2013; Accepted 04 July 2013

\begin{abstract}
European yew (Taxus baccata L.) is a rare species, but is the focus of great interest because of the species recovery attempts and its use in medicine. The aim of this study was to determine the optimum conditions for the development of the young generation of this species. Four-year old yew seedlings were grown under artificial light reduction: 2,8 , and $30 \%$, as well as in full light. The seedlings were then planted in natural conditions in fenced and unfenced areas. The results of six years field studies indicated that the greatest impact on survival was shown by the light conditions from the period before planting under the canopy of trees. Seedlings from the 2 and $8 \%$ of light showed the greatest mortality. The reason was the sudden change in light conditions, because at the time of planting (early spring), there was no reduction of light under deciduous trees. Almost all of the unfenced yew seedlings were grazed by deer, but yew survival in the unfenced group was surprisingly high despite the permanent grazing. This was explained by the high resistance of yew to cutting and the protection of seedlings by a dense layer of Rubus. The results indicated that yew trees require protection against animals for normal development, even if animals have not previously had contact with Taxus and that yew seedlings are very sensitive to sudden changes in light. Both conclusions can be applied in the development of natural and artificial regeneration of European yew and other endangered plants.
\end{abstract}

Additional key words: yew, endangered species, light intensity

Addresses: G. Iszkuło, Institute of Dendrology, Polish Academy of Sciences, Parkowa 5, 62-035 Kórnik, Poland, Faculty of Biological Sciences, University of Zielona Góra, Prof. Z. Szafrana 1, 65-516 Zielona Góra, Poland, e-mail: iszkulo@man.poznan.pl K. Nowak-Dyjeta, M. Sękiewicz, Institute of Dendrology, Polish Academy of Sciences, Parkowa 5, 62-035 Kórnik, Poland

\section{Introduction}

European yew (Taxus baccata L.) is a rare and threatened species in a major part of geographical areas (Schirone et al. 2010; Trober and Ballian 2011).
Reasons for this situation are: long term human impacts (Thomas and Polwart 2003), a weak competitive ability (Iszkuło et al. 2012), and dioecy (Cedro and Iszkuło 2012; Iszkuło et al. 2011). Nevertheless, the genus Taxus (including T. baccata) is widely used in pharmacy, as taxanes are found in the needles and 
bark, which are used to produce a very effective anti-cancer medicine (Wani et al. 1971; Guenard et al. 1993; Iszkuło et al. 2013).

Threats and interest in the pharmaceutical industry are the reason for conservation and restoration programs of yew in many regions of the world (Smith and Cameron 2002; Zhang and Ru 2010; Farris et al. 2012; Katsavou and Ganatsas 2012). European yew is a shade-tolerant species, and although it often grows well in the full sun (Thomas and Polwart 2003; Perrin and Mitchell 2013). However, full sun negatively affects the survival of one-year seedlings in the central Europe climate, so it is suggested to grow this species in the shade (Iszkuło 2010). Nevertheless, little is known so far about the demands and cultivation of this species, especially in the early stages of development. We have no information on the influence of initial shading on the further growth of seedlings. The next most important problem is the impact of animals on European yew populations. In most yew populations in Europe a negative effect of deer on natural regeneration is observed. Taxus baccata is poisonous, nevertheless intense deer browsing is often observed in many places (Mysterud and Østbye 1995; Perrin et al. 2006; Farris and Filigheddu 2008). However, there are no reports which have analysed the impacts of animals which have never encountered Taxus baccata before. Therefore, the following research hypotheses were formulated: 1) the initial shading of seedlings affects the growth, survival and further development of Taxus baccata; 2) protection against animals is necessary for good growth and development of the yew.

\section{Materials and methods}

Seeds for this study were gathered from 10 individuals in the Malinówka nature reserve (south east Poland) and were prepared for germination according to methods described by Suszka (1985). In 2002, germinated seeds were sown in a nursery (geographic coordinates: $\mathrm{N} 52^{\circ} 14^{\prime} 40^{\prime \prime}, \mathrm{E} 17^{\circ} 06^{\prime} 04^{\prime \prime}, 77 \mathrm{~m}$ a.s.l.) under similar light conditions (60\% of PPFD). In 2003, germinated seeds were planted in 4-litre plastic pots. Pots were put into an artificial shading outdoor garden at 2, 8, 30 and 100\% full solar radiation. Two metre-high scaffolding was covered with one or two layers of neutral density woven propylene shade cloth (Agrotex Inc.). The actual degree of light reduction under the screen was confirmed by the simultaneous measurements of photosynthetic active radiation (PAR) inside the screen and within a nearby open area. The Line Quantum Sensors (Apogee Inc.) were used to measure PAR.

In April 2006, four year-old yew seedlings were planted in $24 \times 24 \mathrm{~m}$ plots $(0.056 \mathrm{ha})$ in a $3 \times 3$ $\mathrm{m}$ spacing. Plots were established in the forest managed by Babki Forest District localized near Kórnik,
Września Plateau, Poland (geographic coordinates: N 52 $16^{\prime} 43^{\prime \prime}$, E $17^{\circ} 04^{\prime} 23^{\prime \prime}, 95$ m a.s.l.). Average yearly precipitation here is $544 \mathrm{~mm}$, with average yearly temperature of $8.3^{\circ} \mathrm{C}$ in the Kórnik meteorological station (Cedro and Iszkuło 2011).

The experiment had two treatments (fenced and unfenced) each with three replicate plots (blocks) 24 $\times 24 \mathrm{~m}$ in size, within each 64 seedlings were planted. Distance between plots was between 10 and 20 m. Plots location was mixed - fenced and unfenced plots were not contiguous each other. In each plot were four initial light levels $(2,8,30,100 \%$ of PPFD) schematically distributed on the same scheme. A total of 384 yew trees were planted $(64 \times 3$ blocks $\times 2$ fenced variants).

Plots were established under the canopy of trees of two layers, upper, larch (Larix decidua) and, lower, oak (Quercus robur). Density of larches was 86 trees per hectare, average height was 35.59 (standard error 0.3934 ) and average diameter was 53.61 (standard error 1.869). The density of oaks was reduced before planting in order to improve the growth conditions of yew. After reducing density of oaks was 199 trees per hectare, average height was 26.40 (standard error 0.2980 ) and average diameter was 26.06 (standard error 0.5543).

In the first year of the experiment, in April and at the time of full development of leaves (15 July), light intensity (RPPFD) was measured for each seedling planted, according to the methodology described above (simultaneously within and outside the forest). Each year, measurements of height, survival and grazing of saplings were performed.

The multivariate approach (MANOVA, O'Brien and Kaiser 1985) to repeated measures was used to analyse the survival and height of seedlings. Percent data (seedling survival) were transformed with an arcsine function, which normalised distributions in order to satisfy the assumptions of MANOVA. Between MANOVA subjects, the T-Test was used. Within MANOVA subjects, T-Test, Wilks' Lambda, Pillai's Trace, and Hotelling-Lawley Trace were also examined and gave consistent interpretations in all cases. All data were analysed using JMP 8.0 (SAS Institute Inc.).

\section{Results}

Light measurements in the first year under the canopy of trees, showed the average RPPFD (Relative Photosynthetic Photon Light Intensity) to be $36 \%$ (standard error 0.6545) when tress were leafless (April) and $13.95 \%$ (standard error 0.1807) at the time of full development of leaves (July). The RPPFD did not differ significantly between the variants or the blocks in both analysed periods (data not shown). 
Table 1. MANOVA - Repeated Measures Analysis of T. baccata survival against time and treatments. Initial light means 4-year growth in different light conditions before planting (see text). Bold indicates significant values

\begin{tabular}{lllrr}
\hline Source of variation & \multicolumn{1}{c}{ Test } & F-Value & DF & Prob $>$ F \\
\hline Between subjects & & & & \\
Fencing & F Test & 0.930 & 1 & 0.001 \\
Initial light & F Test & 3.661 & 3 & $<0.0001$ \\
Fencing $\times$ initial & F Test & 0.442 & 3 & 0.110 \\
light & & & & \\
Within subjects & & & & \\
Time & F Test & 15.53 & 5 & $<0.0001$ \\
Time $\times$ fencing & F Test & 10.17 & 5 & $<0.0001$ \\
Time $\times$ initial light & Wilks' Lambda & 0.176 & 15 & 0.052 \\
\hline
\end{tabular}

The highest negative influence on survival was the initial light level (indicating growth over 4 years in 2, 8, 30 and $100 \%$ of PPFD light before planting under the canopy of trees) (Table 1 and Fig. 1). The lowest survival was found for seedlings growing before planting at initial light levels of 2 and $8 \%$. Significantly higher survival was seen at 30 and $100 \%$ of PPFD (Fig. 1). This relationship was similar in the unfenced and fenced variant as demonstrated by the lack of interaction between fencing and initial light (Table 1). There was also a significant effect of fencing on survival, with the unfenced group showing a lower survival rate. The change in survival over time was also different depending on the fencing (significant interaction of time $\times$ fencing - Table 1 ). This was due to the rapid decline in survival in 2008 in the unfenced variant (Fig. 1). Nearly $100 \%$ of grazed seedlings were found in the unfenced group in 2008 (Fig. 2).

In contrast to survival, no significant effect of initial light on the height of yew seedlings was found. The greatest impact was fencing and initial height (Table 2), with the effect of fencing being the most evident. The growth of seedlings was low or even negative in the unfenced variant after the year 2007, unlike the fenced variant, where the annual increment was observed in all of the tested variants of initial light (Fig. 3). The absence or low increases of height in the unfenced variant were the most likely cause of the significant interaction between time and fencing, and between the initial height and light (Table 2, Fig 3). The second reason for the significant interactions between time and the initial height and

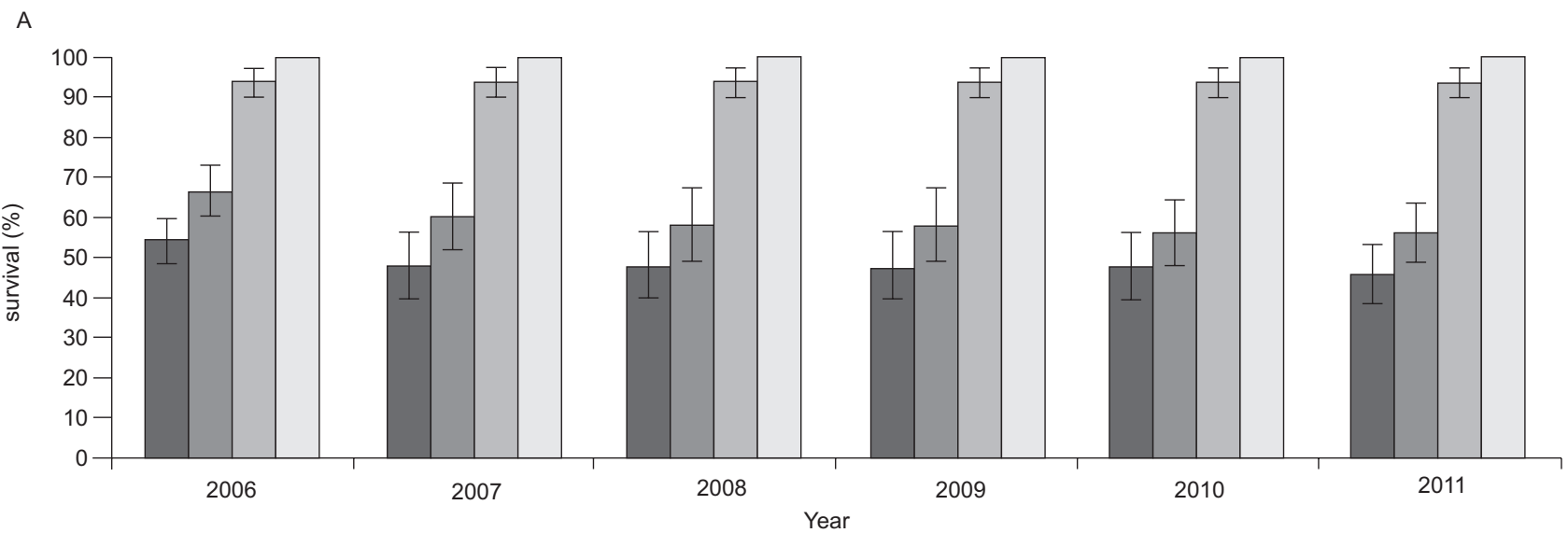

B

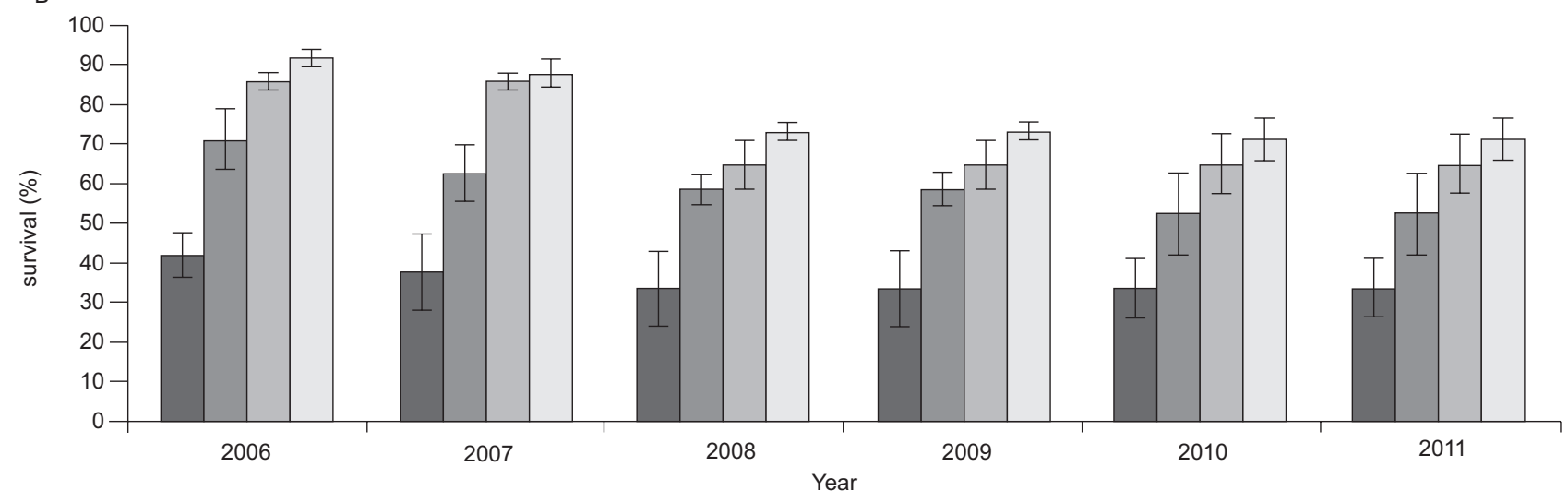

$\square 2 \square 8 \quad \square 30 \quad \square 100$

Fig. 1. The survival ( \pm standard error) of T. baccata seedlings in the fenced (A) and unfenced (B) variant grown before 2006 in different light conditions (2, 8, 30 and 100\% PPFD) 


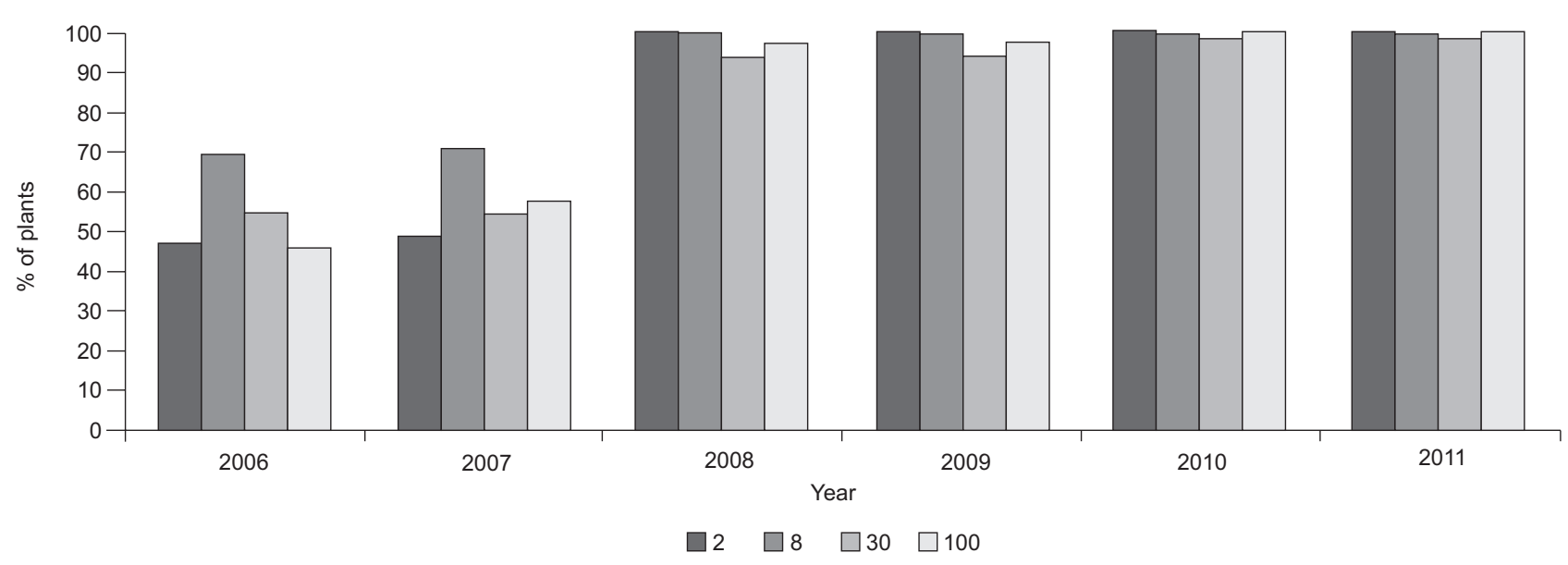

Fig. 2. Percent of grazed T. baccata seedlings in the unfenced variant growing before 2006 in different light conditions (2, 8,30 and $100 \%$ PPFD)

A

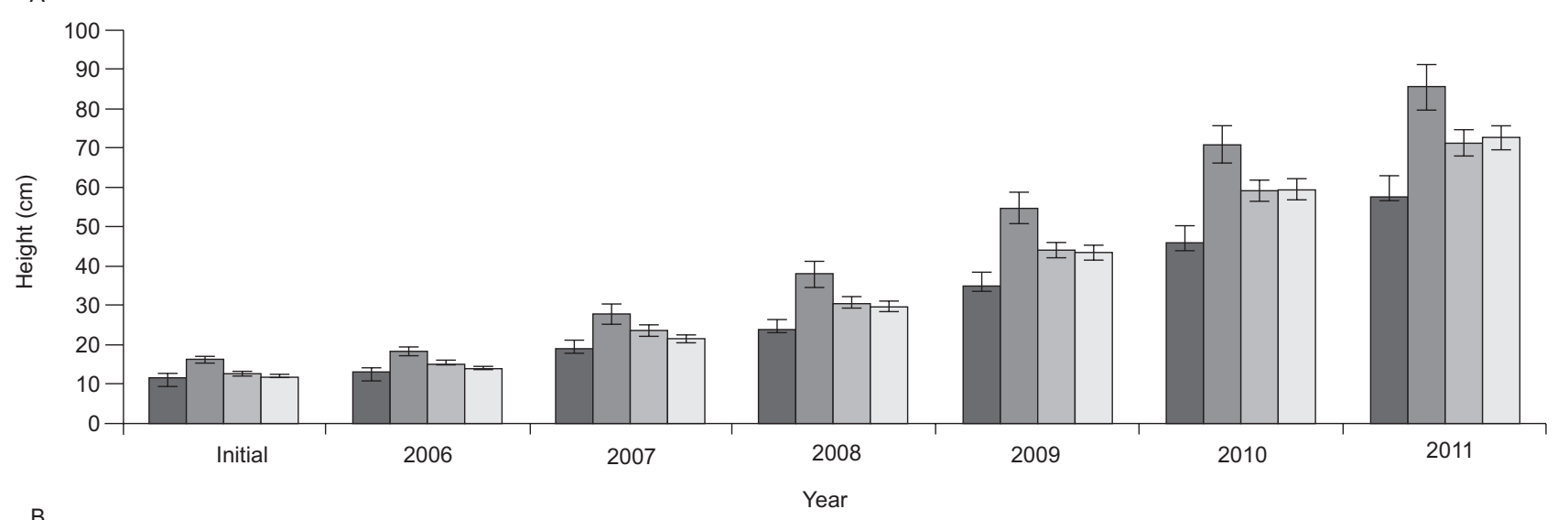

B

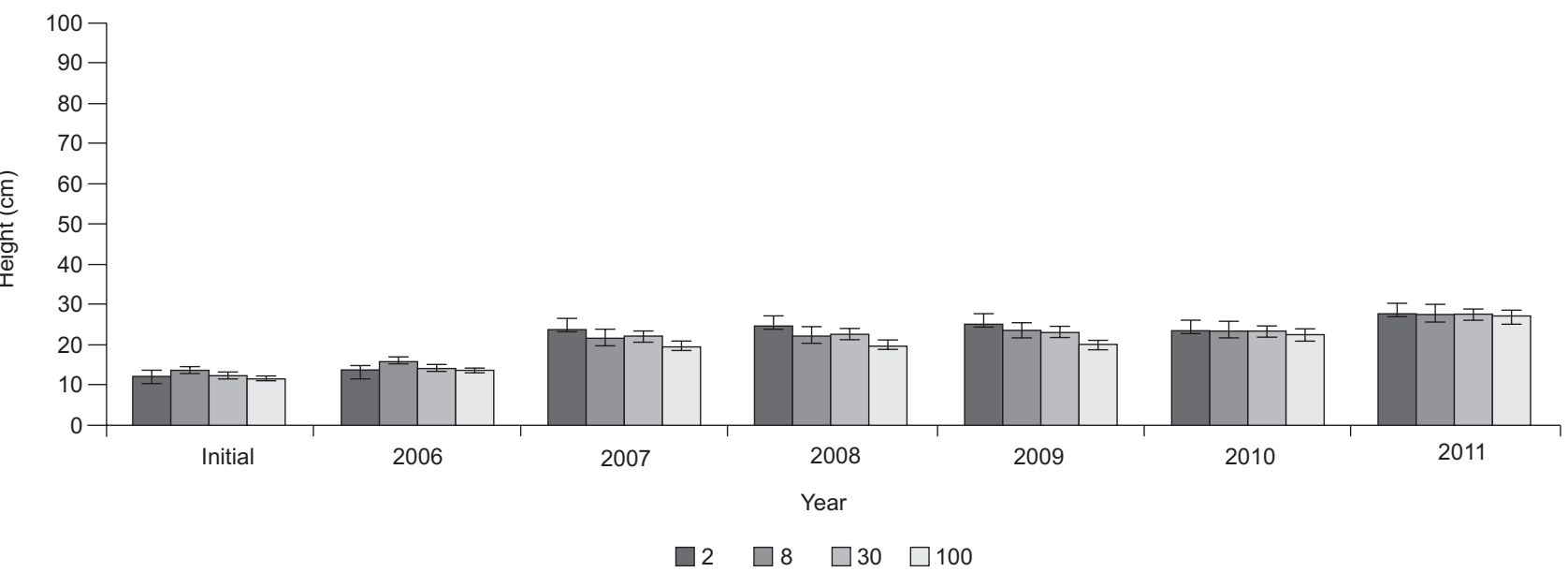

Fig. 3. Mean height ( \pm standard error) of fenced (A) and unfenced (B) T. baccata seedlings growing before 2006 in different light conditions (2, 8, 30 and $100 \%$ PPFD)

light was significantly higher seedlings in the group with $8 \%$ of the initial light in the fenced variant and lack of this dominance (8\%) from 2007 in the unfenced variant (Fig. 3).

\section{Discussion}

This study has demonstrated high deer pressure on Taxus baccata seedlings, as young trees have no chance for normal growth and development without protection. This confirms earlier reports of the nega- 
Table 2. MANOVA - Repeated Measures Analysis of $T$. baccata height against time effect and treatments with initial height as a covariant. Initial light means 4-year growth in different light conditions before planting (see text)

\begin{tabular}{llccc}
\hline \multicolumn{1}{c}{ Source of variation } & \multicolumn{1}{c}{ Test } & Value & DF & Prob $>$ F \\
\hline Between subjects & & & 1 & $<0.0001$ \\
Fencing & F Test & 1.0270 & 3 & 0.1054 \\
Initial light & F Test & 0.0274 & 3 & 0.1133 \\
Fencing $\times$ initial light & F Test & 0.0267 & 1 & $<0.0001$ \\
Initial height & F Test & 0.7195 & 1 & 0.0001 \\
Fencing $\times$ initial height & F Test & 0.0680 & 3 & 0.1030 \\
Initial light $\times$ initial height & F Test & 0.0277 & & 0.0033 \\
Within subjects & & & 5 & $<0.0001$ \\
Time & F Test & 0.0827 & 5 & $<0.0001$ \\
Time $\times$ fencing & F Test & 2.0860 & 5 & 0.0410 \\
Time $\times$ initial height & F Test & 0.2158 & 15 & 0.8917 \\
Time $\times$ initial light & Wilks' Lambda & & \\
\hline
\end{tabular}

tive effects of deer on yew seedlings (Piovesan et al. 2009; Farris and Filigheddu 2008). Almost all yew trees were grazed in the unfenced variant. Nevertheless, it is surprising that their survival was relatively high $(33 \%$ to $71 \%$ in the unfenced group in the last year of the experiment). Yew is a species that is resistant to cutting, and is widely used as a hedges species (Thomas and Polwart 2003). The second reason for the high survival of yew was also the dense cover of Rubus fruticosus agg. L., making browsing difficult below 25-28 cm. This was one of the reasons that the height of grazed seedlings did not change significantly from the third year after planting in the unfenced group. Another characteristic was the highest percentage of grazed seedlings from the group with initial light of $8 \%$ in the unfenced variant. Seedlings from $8 \%$ of PPFD were significantly higher than seedlings from other light variants and this greater exposure was probably a direct reason for the greater grazing. The positive impact of prickly plants on yew regeneration has been previously demonstrated in a Mediterranean area, where spiny shrubs mechanically protected species from browsing animals (Watt 1926; Garcia et al. 2000; Farris and Filigheddu 2008). Despite the information that shaded plants are more strongly browsed than plants growing in full sun (Baraza et al. 2010) in this study we did not find relationship between fencing (browsing) and initial light.

Initial light (before planting under canopy) had a significant influence on the survival of yew. In the first year of the experiment, the majority of plants that had been grown under $2 \%$ and $8 \%$ died out. This was not caused by the poor condition of the trees growing in this light condition, because seedlings from $8 \%$ exhibited the best parameters (survival and dry weight) (Iszkuło 2010). The direct reason for the high mortality could be a sudden change in light conditions. Seedlings were planted under the canopy of trees, but this was done in early spring, when both larch and oak were leafless (36\% PPFD). Plants growing in low light develop leaves with large surface areas relative to their weight. However, at higher light intensities the area-to-mass ratio decreases, and the plant reduces the risk of an excessive temperature increase and desiccation. A similar relationship was also demonstrated in Taxus baccata (Wyka et al. 2008; Iszkuło 2010; Perrin and Mitchell 2013) and Taxus brevifolia (Mitchell 1998). Light changes also influences on the biomass allocation in plants. Seedlings growing in the shade invest primarily in above-ground part of plant. A sudden exposure to light causes higher transpiration rate and in consequently water deficit (Walters and Reich 1996; Larcher 2003). Because the most likely cause of high mortality of yew was a sudden change of lighting, it can be concluded that the rapid uncovering of seedlings can result in a significant reduction in their numbers. Therefore, the production of planting material cannot take place under too much shade (8\% PPFD is too low a level of light), because the losses associated with the lack of rapid acclimation to higher light levels can be very large. For both natural and artificial regeneration, shading would result in a progressive, long-term increase in light levels.

Contrary to sudden exposure to light, sudden shading did not have negative effects for yew. Taxus baccata is a typical shade tolerant species (Brzeziecki and Kienast 1994) and adaptation to shade probably is easier. Shade tolerant species have also a relatively low plasticity to sudden exposure to light (Bazzaz and Carlson 1982; Valladares et al. 2002).

Despite the strong influence of light conditions before planting on survival, yew trees showed no effect of this factor on the height of trees (Table 2). However, a significant impact was seen for initial height, which was clearly illustrated by the $8 \%$ of initial light 
variant. This variant dominated from the first to the last years in the fenced group. Similarly, in the case of other species, an effect of initial height on annual growth has been shown (Ammer et al. 2008), which resulted in the stability of height positions in young stands (Ruha et al. 1997).

High interest of the pharmaceutical industry and programs for the protection and recovery of endangered species require the development of treatment methods for the promotion of natural regeneration and planting in natural and artificial conditions. These studies showed that yew saplings were very sensitive to light changes. In the case of regeneration under a canopy of trees, seasonal changes in light due to foliage loss should be taken into account. It is necessary to protect plants from browsing, even in areas where animals have not had previously contact with planted species.

\section{Acknowledgments}

This study was partially supported by the Institute of Dendrology, Polish Academy of Sciences, Kórnik, Poland. We thank Dr. Mieczysław Kasprzyk (Forest District Manager) and Mr. Jacek Szaj (Regional Directorates of the State Forests) their kindness and help in our fieldwork.

\section{References}

Ammer C., Stimm B., Mosandl R. 2008. Ontogenetic variation in the relative influence of light and belowground resources on European beech seedling growth. Tree Physiology 28: 721-728.

Baraza E., Zamora R., Hodar J.A. 2010. Species-specific responses of tree saplings to herbivory in contrasting light environments: An experimental approach. Ecoscience 17: 156-165.

Bazzaz F.A., Carlson R.W. 1982. Photosynthetic acclimation to variability in the light environment of early and late successional plants. Oecologia 54: 313-316.

Brzeziecki B., Kienast F. 1994. Classifying the life-history strategies of trees on the basis of the Grimian model. Forest Ecology and Management 69: 167-187.

Cedro A., Iszkuło G. 2011. Do females differ from males of European yew (Taxus baccata L.) in dendrochronological analysis? Tree-Ring Research 67: 3-11.

Farris E., Filigheddu E. 2008. Effects of browsing in relation to vegetation cover on common yew (Taxus baccata L.) recruitment in Mediterranean environments. Plant Ecology 199: 309-318.

Farris E., Fenu G., Baccheta G. 2012. Mediterranean Taxus baccata woodlands in Sardinia: a characteri- zation of the EU priority habitat 9580 . Phytocoenologia 41: 231-246.

Garcia D., Zamora R., Hodar J.A. 2000. Yew (Taxus baccata L.) regeneration is facilitated by fleshy-fruited shrubs in Mediterranean environments. Biological Conservation 95: 31-38.

Guenard D., Gueritte-Voegelein F., Poiter P. 1993. Taxol and taxotere: discovery, chemistry and structure activity relationship. Accounts of Chemical Research 26: 160-167.

Iszkuło G. 2010. Success and failure of endangered tree species: low temperatures and low light availability affect survival and growth of European yew (Taxus baccata L.) seedlings. Polish Journal of Ecology 58: 259-271.

Iszkuło G., Jasińska A.K., Sobierajska K. 2011. Dendroecological differences between Taxus baccata males and females in comparison with monoecious Abies alba. Dendrobiology 65: 55-61.

Iszkuło G., Didukh Y., Giertych M.J., Jasińska A.K., Sobierajska K., Szmyt J. 2012. Weak competitive ability may explain decline of Taxus baccata. Annals of Forest Science 69: 705-712.

Iszkuło G., Kosiński P., Hajnos M. 2013. Sex influences the taxanes content in Taxus baccata. Acta Physiolgiae Plantarum 35: 147-152.

Katsavou I., Ganatsas P. 2012. Ecology and conservation status of Taxus baccata population in NE Chalkidiki, northern Greece. Dendrobiology 68: 55-62.

Larcher W. 2003. Physiological plant ecology. Berlin, Springer.

Mitchell A.K. 1998. Acclimation of Pacific yew (Taxus brevifolia) foliage to sun and shade. Tree Physiology 18: 749-757.

Mysterud A., Ostbye E. 1995. Roe deer Capreolus capreolus feeding on yew Taxus baccata in relation to bilberry Vaccinium myrtillus density and snow depth. Wildlife Biology 1: 249-253.

O’Brien R.G., Kaiser M.K. 1985. MANOVA method for analyzing repeated measures designs: an extensive primer. Psychological Bulletin 97: 316333.

Perrin P.M., Kelly D.L., Mitchell F.J.G. 2006. Longterm deer exclusion in yew-wood and oakwood habitats in southwest Ireland: Natural regeneration and stand dynamics. Forest Ecology and Management 236: 356-367.

Perrin P.M. Mitchell FJ.G. 2013. Effects of shade on growth, biomass allocation and leaf morphology in European yew (Taxus baccata L.). European Journal of Forest Research 132: 211-218.

Piovesan G., Saba E.P., Biondi F., Alessandrini A., Di Filippo A., Schirone B. 2009. Population ecology of yew (Taxus baccata L.) in the Central Apennines: spatial patterns and their relevance for conservation strategies. Plant Ecology 205: 23-46. 
Reich P.B., Wright I.J., Cavender-Bares J., Craine J.M., Oleksyn J., Westoby M., Walters M.B. 2003. The evolution of plant functional variation: Traits, spectra, and strategies. International Journal of Plant Sciences 164: 143-164.

Ruha M., Hokka H., Varmola M., Salminen H. 1997. Stability of height positions in young naturally regenerated stands of Scots pine. Forest Ecology and Management 97: 155-163.

Smith R.F., Cameron S.I. 2002. Domesticating ground hemlock (Taxus canadensis) for producing taxanes: a case study In: Mackay WA (ed.) 29th Annual Meeting of the Plant Growth Regulation Society of America. Halifax, Canada, pp 40-45.

Schirone B., Ferreira R.C., Vessella F., Schirone A., Piredda R., Simeone M.C. 2010. Taxus baccata in the Azores: a relict form at risk of imminent extinction. Biodiversity and Conservation 19: 15471565.

Suszka B. 1985. Conditions for after-ripening and germination of seeds and for seedling emergence of English yew (Taxus baccata L.). Arboretum Kórnickie 30: 285-338.

Thomas P.A., Polwart A. 2003. Taxus baccata L. Biological Flora of the British Isles 229. Journal of Ecology 91: 489-524.

Trober U., Ballian D. 2011. Genetic characterization of English yew (Taxus baccata L.) populations in
Bosnia and Herzegovina. European Journal of Forest Research 130: 479-489.

Valladares F., Chico F.J., Aranda I., Balaguer L., Dizengremel P., Manrique E., Dreyer E. 2002. The greater seedling high-light tolerance of Quercus robur over Fagus sylvatica is linked to a greater physiological plasticity. Trees 16: 395-403.

Walters M.B., Reich P.B. 1999. Low-light carbon balance and shade tolerance in the seedlings of woody plants: do winter deciduous and broadleaved evergreen species differ? New Phytologist 143: 143-154.

Wani M.C., Taylor H.L., Wall M.E., Coggon P., McPhail A.T. 1971. Plant antitumour agents VI. The isolation and structure of taxol, a novel antileukemic and antitumour agent from Taxus brevifolia. Journal of the American Chemical Society 93: 2325-2327.

Watt A.S. 1926. Yew communities on the South Downs. Journal of Ecology 14: 282-316.

Wyka T., Robakowski P., Zytkowiak R. 2008. Leaf age as a factor in anatomical and physiological acclimative responses of Taxus baccata L. needles to contrasting irradiance environments. Photosynthesis Research 95: 87-99.

Zhang J.T., Ru W.M. 2010. Population characteristics of endangered species Taxus chinensis var. mairei and its conservation strategy in Shanxi, China. Population Ecology 52: 407-416. 